Herz 2019 · 44:266

https://doi.org/10.1007/s00059-017-4666-y

Published online: 14 December 2017

(c) Springer Medizin Verlag GmbH, ein Teil von Springer Nature 2017

CrossMark

O. Candan · C. Gecmen · A. Kalaycı · E. Bayam · A. Guner · S. Gunduz - S. Cersit · M. Ozkan

Cardiology Clinic, Kartal Kosuyolu Heart, Training and Research Hospital, Kartal, Turkey

\title{
Prognostic information on HCM patients via speckle tracking
}

value was $80 \%$ and the negative predictive value was $60 \%$ for GLPS $<-11.9$.

Regarding the HCM risk score, only the positive predictive value of GLPS was found to be high whereas the negative predictive value of GLPS as well as twist, as stated by Rigopoulos et al., was identified to be higher in terms of arrhythmia development. In light of these data, the speckle-based parameters can provide prognostic information on the HCM patient group in terms of arrhythmia development and/or sudden cardiac death $[2,3]$. They can furthermore provide additional information to the MOGE(S) classification, as the authors also specified [4]. There is a need for studies including more patients and in which clinical follow-up is monitored.

\section{Corresponding address}

\section{O. Candan, MD}

Cardiology Clinic, Kartal Kosuyolu Heart, Training and Research Hospital 34846 Kartal, İstanbul, Turkey oz_candan@hotmail.com

Conflict of interest. O.Candan, C. Gecmen, A. KalaycI, E. Bayam, A. Guner, S. Gunduz, S. Cersit, and M. Ozkan declare that they have no competing interests.

\section{References}

1. Candan O, Gecmen C, Kalaycı A et al (2017) Left ventricular twist in hypertrophic cardiomyopathy: Predictor of nonsustained ventricular tachycardia Herz 16. https://doi.org/10.1007/s00059-0174633-7

2. McKenna WJ, Sadoul N, Slade AK, Saumarez RC (1994) The prognostic significance of nonsustained ventricular tachycardia in hypertrophic cardiomyopathy. Circulation 90(6):3115-3117

3. Zhang HJ, Wang H, Sun Tet al (2014) Assessment of left ventricular twist mechanics by speckle tracking echocardiography reveals association between LV twist and myocardial fibrosis in patients with hypertrophic cardiomyopathy. Int J Cardiovasc Imaging 30(8):1539-1548

4. Westphal JG, Rigopoulos AG, Bakogiannis C et al (2017) The MOGE(S) classification for cardiomyopathies: current status and future outlook. Heart Fail Rev 22(6):743-752 